\title{
Untersuchungen über den Komplementgehalt des Blutes von Geisteskranken, mit besonderer Beriicksichtigung der progressiven Paralyse.
}

\author{
Von \\ Dr. Otto Rössle, \\ Assistenzarzt der Provinzial-Irrenanstalt bei Neustadt i. Holstein.
}

(Eingegangen am 12. Januar 1913.)

Unter den in den letzten 10 Jahren erschienenen, sehr zahlreichen Arbeiten über den Hämolysingehalt des Blutes, sind auffallend wenige, die sich mit dem Serum von Geisteskranken beschäftigen. Es ist ja ersichtlich, daß es zunächst bei Infektionskrankheiten, akuter oder chronischer Natur, von Interesse sein mußte, ein Urteil über die baktericiden Schutzkräfte des Organismus zu erhalten. Man konnte doch hoffen von einer möglichst tief gehenden Kenntnis der einschlägigen Verhältnisse Anhaltspunkte für die prognostische Beurteilung eines Krankheitsfalles ev. sogar für therapeutische Beeinflussung zu erhalten. So liegen über die verschiedensten Infektionskrankheiten Untersuchungen vor, deren Ergebnisse jedoch für die Praxis bisher keine wesentliche Bedeutung erlangt haben. Kentzler fand bei Lungentuberkulose Verhältnisse, die nicht von normalen abwichen; - in einer umfangreichen Monographie Moros, die sich mit dem Alexingehalt des kindlichen Serums befaßt, wird der Alexinbestimmung prognostische Bedeutung zugesprochen.

In der psychiatrischen Literatur der letzten Jahre findet sich nur eine Arbeit von Gay und A yer, die bei Geisteskranken Bestimmungen über den Alexingehalt vornahmen. Es wurden keine wesentlichen Besonderheiten, bezüglich der Komplementmenge bei den einzelnen Seren gefunden. Der Alexingehalt des Frauenblutes war im ganzen etwas geringer als der bei den Männern.

Erst durch die in den letzten Jahren, besonders in Hinsicht auf die postsyphilitischen Krankheitsprozesse so erfolgreich angewandten serologischen Untersuchungsmethoden, ist die Aufmerksamkeit wieder auf die Komplemente des Blutserums gelenkt worden. So berichtet Eliasberg, der bei Lepra Analexie fand, über das Fehlen des Komplements im Blute der an progressiver Paralyse leidenden Kranken. Neuerdings hat $\mathrm{Kafka}$, der diesen Dingen besonders nachgegangen ist, die An- 
gaben von Eliasberg insofern bestätigt, als er bei 9 von 24 Paralytikern Analexie fand. Diese Mitteilungen scheinen mir besonders bemerkenswert zu sein in Hinsicht auf therapeutische Versuche, mit denen in der letzten Zeit bei der Paralyse Erfolge gesehen worden waren. Bekanntlich hat man neuerdings die alte Erfahrung, da $\beta$ bei Paralysen, die entzündliche oder septische Krankheitsprozesse überstanden hatten, eine günstige Beeinflussung des paralytischen Krankheitsprozesses eintreten kann, in der Weise praktisch angewandt, daß man - ähnlich wie bei der Tuberkulose-Therapie - fortgesetzte Injektionen von Tuberkulin machte und man hat tatsächlich vielfach Besserungen des paralytischen Krankheitsprozesses beobachtet. Da nachgewiesenermaßen eine vorübergehende Steigerung des Alexingehaltes mit vorsichtig applizierten Tuberkulindosen möglich ist, so wäre daran zu denken, ob die Wirkung dieser Einspritzungen nicht auch hier, wie bei der Tuberkulose, auf eine Erhöhung der hämolytischen Schutzkräfte des Organismus zurückzuführen ist. Auch die neuerdings so warm empfohlenen Injektionen von Nuclein, bei denen eine beträchtliche Leukocytose entsteht, könnten in ähnlichem Sinne wirken. Ist doch die nahe Beziehung der komplementären Stoffe zu den Leukocyten bekannt, wenn wir auch heute noch über die sichere Bildungsstätte der Komplemente im unklaren sind. Es schien mir unter diesen Verhältnissen der Mühe wert, durch eigene Versuche zur Klärung dieser Verhältnisse beizutragen. Schon gelegentlich der Anstellung von quantitativen Hemmungskörperbestimmungen war mir bei einigen angesetzten Proben aufgefallen, wie sehr verschieden sich die einzelnen Seren bezüglich ihres hämolytischen Wertes vêrhalten. Auch bei der Austitrierung von Meerschweinchenserum war mir einmal aufgefallen, daß ich entgegen dem gewöhnlichen Wert von $0,04-0,06$ in einem Fall erst in 0,09 cem die eben lösende Dosis fand, obwohl es sich immer um Tiere derselben Zucht gehandelt hatte. Es stellte sich später heraus, daß das minderwertige Serum von einem Tier stammte, das am Tage vorher einen Wurf Junge abgesetzt hatte. Es ist mir nicht bekannt, ob beim Menschen ähnliches beobachtet wurde. Moro berichtet, daß bei Neugeborenen der Komplementgehalt zunächst geringer als die Norm ist.

Im ganzen konnte ich das Blut von 175 Kranken untersuchen; es waren 65 Kranke aus der Gruppe der Dementia praecox, 39 Epileptiker, 31 Idioten, 2 Manisch-Depressive, 13 Paralysen, 19 vielfach recht kachektische Kranke mit Psychosen des Rückbildungsalters, ferner noch 5 Alkoholiker und 1 Fall von multipler Sklerose. Irgendwelche besonderen Einflüsse, die auf den Alexingehalt des Blutes wirken können, lassen sich bei dem Krankenmaterial einer Anstalt, das sich genau unter denselben gleichmäßigen Lebensbedingungen befindet, ausschalten. Wo besondere Verhältnisse im körperlichen Zustand eines 
Patienten vorlagen, ist dies bei der Besprechung der Resultate besonders berücksichtigt. Von einer Trennung der Ergebnisse nach dem Geschlecht der untersuchten Patienten wurde bei der Besprechung der Befunde abgesehen, da sich bald gezeigt hatte, daß auffallende Unterschiede nicht vorlagen. Im Gegensatz zu Gay und Ayer, die berichten, da 3 der Alexingehalt bei Frauen im ganzen etwas geringer war als bei Männern, zeigte sich, daß ein durchschnittlich allerdings nur um weniges höherer Alexingehalt bei den Frauen vorlag. Es mag dies daran liegen, daß die von den weiblichen Patienten stammenden Seren in den Vormittagsstunden entnommen worden waren, während bei den Männern die Blutentnahme in den Nachmittag- und Abendstunden vorgenommen wurde. Nach den Angaben von Eliasberg soll in den Zeiten der Verdauung eine vorübergehende Verminderung des Alexingehalts vorhanden sein. Es wäre bei weiteren Versuchen darauf zu achten, daß diese Verhältnisse möglichst gleichmäßig gestaltet würden.

Bezüglich der Methodik, deren ich mich zur Ausführung der Untersuchungen bediente, möchte ich folgendes erwähnen:

Da die beiden Teile des Hämolysins - Komplement und Amboceptor - sich in ihren Mengenverhältnissen teilweise derart ersetzen können, daß wenig Amboceptor mit viel Komplement dieselbe Wirkung hervorbringen kann, wie viel Amboceptor mit wenig Komplement, so ist ein sicheres Urteil über den Komplementgehalt eines Serums nur dann zu erhalten, wenn der Amboceptor in seinen Mengenverhältnissen annähernd bekannt ist. Man wird also möglichst Immunamboceptor zum Versuch verwenden und, um eine Einwirkung der im Serum vorhandenen Normalamboceptoren auf das Komplement auszuschalten, wird es nötig sein, dieselben vorher zu entfernen.

Ich bediente mich zu diesem Zwecke der Kältetrennungsmethode: frisches, 3 mal gewaschenes Hammelblut und das zu untersuchende klare Serum werden zunächst längere Zeit auf Eis gekühlt, dann werden mit kalten Pipetten in eisgekühlte Zentrifugengläser je 0,5 ccm Hammelblut eingefüllt, die Gläser einige Zeit in Eis stehen gelassen und $2 \mathrm{ccm}$ des kalten Serums zugefügt. Das Ganze wird eine bis eineinhalb Stunden in den Eisschrank gestellt, die Gläser werden hierauf möglichst kurz im kalten Zimmer mit einer elektrischen Zentrifuge zentrifugiert und das Serum abgegossen.

Das Verfahren ist etwas penibel, da es bei nicht exaktem Arbeiten passieren kann, daß das Serum nach dem Zentrifugieren hämolytisoh geworden ist. Man muß besonders darauf achten, daß die Manipulationen beim Herausnehmen der Gläser aus dem Eis recht flink vor sich gehen und daß möglichst schnell zentrifugiert wird. Wenn man Zentrifugengläser von demselben Gewicht benützt, so kann man, da gleiche Serum- und Blutmengen in allen Gläsern sind, sich sehr wohl einer 
elektrischen Zentrifuge bedienen, ohne daß man fürchten muß, durch das Tarieren der Gläser Zeit zu verlieren. Die Zimmertemperatur konnte während des Zentrifugierens zwischen $5^{\circ}-9^{\circ}$ gehalten werden, so daß es fast immer gelang, das Serum unverändert klar zu erhalten, wovon man sich in jedem einzelnen Fall durch Vergleich mit dem unbehandelten Serum überzeugen kann. In einigen wenigen Fällen konnte ich allerdings konstatieren, daß das Serum während des Zentrifugierens deutlich hämolytisch geworden war. Es waren dies, wie ich mich beim folgenden Versuch überzeugen konnte, Seren, die auch nachher noch reichlichen Komplementgehalt zeigten.

Von jedem Serum wurden 7 Gläser zum Versuch angesetzt in fallenden Mengen von : 0,5 - 0,3-0,2-0,15-0,1-0,05-0,025 ccm. Sämtliche Gläser wurden mit Kochsalz auf das einheitliche Volumen von $1 \mathrm{ccm}$ gebracht, eine halbe Stunde bei $37^{\circ}$ in den Brutschrank gestellt und nach dieser Zeit das mit Amboceptor in 3 fach lösender Dosis beladene Hammelblut, das eine Stunde bei $37^{\circ}$ gehalten war, hinzugefügt. Die Gläser wurden tüchtig geschüttelt und auch während ihres Aufenthalts im Brutschrank noch mehrfach tüchtig durchgeschüttelt. Das Resultat wurde nach 2 Stunden abgelesen.

Um mir ein Urteil über den Erfolg der Kälteabsorption der Normalamboceptoren in den zu prüfenden Seren zu bilden, wurde von den Blutsedimenten eine derartige Menge aufgeschwemmt, daß in $1 \mathrm{ccm}$ Kochsalzaufschwemmung der Gehalt an Hammelblut einer 5 proz. Lösung entsprach. Hierzu wurde Meerschweinchenkomplement in einer Dosis hinzugefügt, die allein nicht imstande war, $1 \mathrm{ccm} 5$ proz. Hammelblutaufschwemmung deutlich hämolytisch zu beeinflussen. Es zeigte sich dabei in allen Fällen eine mehr oder weniger intensive Hämolyse.

Vom Erfolg der Absorption der Normalamboceptoren in der Kälte, konnte ich mich auch dadurch überzeugen, daß ich vorbehandeltes und nicht vorbehandeltes Serum inaktivierte und in entsprechenden Mengen mit Meerschweinchenkomplement zur Hämolyse ansetzte. In den Gläsern mit vorbehandeltem Serum trat meist keine Spur von Hämolyse auf, während in den Gläsern mit unbehandeltem Serum meist mehr oder weniger deutliche Hämolyse zu konstatieren war. In einigen Fällen waren allerdings auch im unbehandelten Serum keine Normalamboceptoren nachzuweisen, von diesen wird später noch zu reden sein. Einige Male sah ich auch, daß in Versuchen mit vorbehandeltem Serum noch eine partielle Hämolyse eintrat; es deutet dies darauf hin, daß bei der Kälteabsorption nicht alle Amboceptoren entfernt wurden. Es könnten also im Hauptversuch diese das Resultat in ungünstigem Sinne beeinflussen. Dieser Fehler darf jedoch wohl als ein minimaler bezeichnet werden, da die Bedingungen für sein Entstehen nur selten beobachtet werden konnten und da es sich bei Untersuchungen über einen 
so empfindlichen biologischen Prozeß, wie ihn die Hämolyse darstellt, doch immer nur um annähernde Vergleichswerte handeln kann. Bei weiteren Untersuchungen könnte der Einfluß etwaiger zurückgebliebener Normalamboceptoren vielleicht dadurch wesentlich vermindert werden, daß der Immunamboceptor im Versuch in einer größeren als der 3 fachen Menge zur Verwendung kommt.

Um einen leichten Utberblick über die Resultate der Untersuchungen zu ermöglichen sind dieselben untenstehend in Form einer Tabelle dargestellt, in der die Resultate nach Krankheitsformen getrennt und für die einzelnen Serummengen in Prozentzahlen dargestellt sind. Es wurde aus jeder Versuchsreihe dasjenige Glas herausgegriffen, in dem zuerst eine deutliche Kuppe, also Hemmung auftrat, da der Alexingehalt eben nicht mehr ausreichte, um die gesamte Menge Hammelblut aufzulösen. In der ersten Spalte der Tabelle sind die in den 7 Gläsern eines Versuchs jeweilig verwandten Serummengen verzeichnet, die folgenden Zahlen geben immer an, wann bei den einzelnen Krankheitsgruppen zuerst Hemmung auftrat. In der letzten Spalte der Tabelle sind für die einzelnen Serummengen die Durchschnittswerte für alle überhaupt untersuchten Seren zusammen angegeben, um einen Vergleich der einzelnen Krankheitsgruppen mit der Gesamtheit zu ermöglichen. Die Alkoholiker, die Manisch-Depressiven und die multiple Sklerose wurden wegen der geringen Zahl der Fälle in der Tabelle nicht berücksichtigt.

\begin{tabular}{l|r|r|r|r|r|r}
\hline $\begin{array}{c}\text { Serum- } \\
\text { mengen } \\
\text { ccm }\end{array}$ & $\begin{array}{c}\text { Dementia } \\
\text { praecox }\end{array}$ & Epilepsie & Idioten & Paralyse & $\begin{array}{c}\text { Senile Er- } \\
\text { krankungen }\end{array}$ & $\begin{array}{c}\text { Durchschnitts- } \\
\text { werte von allen } \\
\text { Seren zu- } \\
\text { sammengestellt }\end{array}$ \\
\hline \hline 0,025 & 19,5 & 23,1 & 3,3 & 15,4 & 31,6 & 16,2 \\
0,05 & 32,4 & 35,8 & 26,4 & 30,8 & 21,1 & 31,3 \\
0,1 & 20,9 & 12,8 & 30,6 & 15,4 & 21,1 & 20,4 \\
0,15 & 8,6 & 12,8 & 13,4 & - & 15,7 & 10,2 \\
0,2 & 7,6 & 10,2 & 13,4 & - & - & 7,7 \\
0,3 & 2,9 & 2,6 & 6,6 & 7,7 & - & 4,2 \\
0,5 & 7,6 & 2,6 & 6,6 & 30,8 & 10,4 & 9,6 \\
\hline
\end{tabular}

Es ist daraus ersichtlich, daß einige nicht unwesentliche Unterschiede bei den einzelnen Krankheitsformen zu Tage treten. Im allgemeinen pflegt bei 0,05 am häufigsten die Hemmung aufzutreten, bei 0,025 tritt sie annähernd um die Hälfte seltener auf, bei der Serummenge von 0,1 beträgt die Durchschnittszahl ungefähr zwei Drittel derjenigen von 0,05 . Von 0,1 an aufwärts fallen jedoch die Durchschnittszahlen sehr schnell auf niedrige Werte, in den ersten drei Spalten sind annähernd 70 Prozent der Gesamtwerte enthalten. Es dürften also diejenigen Seren besonderes 
Interesse beanspruchen, die eine wesentliche Abweichung von diesen allgemeinen Werten aufweisen. Besonderes Interesse beanspruchen hiervon diejenigen Fälle, die in Reihe 7 vermerkt sind bei denen also schon bei $0,5 \mathrm{ccm}$ Hemmung auftrat, in einer großen Zahl dieser Fälle war überhaupt keine Spur Hämolyse nachzuweisen, hiervon soll später genauer die Rede sein. Zunächst sei erwähnt, daß auffallende .Unterschiede bei der Epilepsie und der Dementia praecox nicht hervortreten. Wie man sieht, bevorzugen beide Krankheitsformen die niedrigen Serumwerte, besonders fällt die Epilepsie durch hohe Ziffern in den ersten beiden Spalten auf; während in der 7. Reihe im Gegensatz zur Dementia praecox, bei der sich dort 7,6\% verzeichnet finden, nur $2,6 \%$ hemmen. Die hohe Ziffer bei der Dementia praecox ist durch Fälle bedingt, die fast durchweg in gewissem Sinne bemerkenswert sind; auf sie soll später bei der Besprechung der Paralyse zurückgekommen werden. Die mittleren Serumwerte zeigen bei den erstgenannten Krankheitsgruppen keine auffälligen Besonderheiten, die Zahlen, die wir dort finden, entsprechen ungefähr dem allgemeinen Durchschnitt. Man kann daraus schließen, daß der Komplementgehalt des Blutes der beiden Krankheitsgruppen ein verhältnismäßig hoher ist, besonders bei der Epilepsie. Um etwaige Änderungen in den Anfallszeiten bei der letzteren Krankheit kennen zu lernen, wurden mehrere Seren unmittelbar nach den Anfällen entnommen, es zeigte sich jedoch, daß keine wesentlichen Differenzen nachzuweisen waren und es wurde von weiteren Untersuchungen in dieser Richtung Abstand genommen.

Beim Vergleich der Idiotie mit den beiden erstgenannten Gruppen sehen wir in der ersten Reihe eine Zahl, die weit hinter allen in derselben Reihe genannten Zahlen zurückbleibt; nur bei 3,4\% der Idioten ist der Komplementgehalt ein so hoher, daß erst bei der Serummenge von 0,025 Hemmung auftritt. Auch die Zahl in der zweiten Reihe ist noch deutlich kleiner als diejenigen in den ersten beiden Spalten, dagegen tritt bei den meisten Idioten die Hemmung schon bei $0,1 \mathrm{ccm}$ Serum auf.

Der Komplement bei der Idiotie wurde also um ein beträchtliches geringer gefunden wie bei der Dementia praecox und der Epilepsie.

Wenden wir uns zur Paralyse. Die Tabelle zeigte in den ersten drei Reihen, die dem allgemeinen Durchschnitt recht nahe kommen, Zahlen, die als verhältnismäßig hohe zu bezeichnen sind. Zwei mittlere Spalten fallen hier ganz aus, dafür zeigt aber die letzte Spalte die enorme Zahl von $30,8 \%$. Die Paralyse soll im folgenden gesondert besprochen werden.

Zieht man im Vergleich mit der Paralyse die in der letzten Spalte verzeichneten Psychosen des Greisenalters heran, bei denen es sich um vielfach in ihrem Kräftezustand aufs äußerste reduzierte kachektische Kranke handelt, so überraschen hier wieder die auffallend hohen Ziffern 
in den ersten drei Reihen. Sie zeigen, daß der Komplementgehalt bei einem vielfach recht debilen Krankenmaterial als ein verhältnismäßig hoher gefunden wurde. Allerdings findet sich auch hier nächst der Paralyse in der 7. Reihe die nächst höhere Zahl.

Die Resultate bei den Alkoholikero bieten nichts Bemerkenswertes. Der Komplementgehalt war durehschnittlich ein ziemlich hoher. Die komplementvermindernde Wirkung des Alkohols konnte in diesen Fällen nicht mehr nachgewiesen werden, da es sich um Kranke handelt, die schon längere Zeit sich in der Anstalt befanden. UUber die zwei Fälle von manisch-depressivem Irresein ist nichts zu erwähnen. Bei einer multiplen Sklerose, die körperlich recht geschwächt ist, fand sich auffallend wenig Komplement.

Hervorgehoben sei hier noch, daß die in der 7. Spalte verzeichneten Fälle meist solche sind, bei denen auch bei $0,5 \mathrm{ccm}$ Serum nicht nur eine Kuppe, sondern totale Hemmung zu finden war.

Die Verhältnisse bei der Paralyse sind von ganz besonderem Interesse. Ich weiß sehr wohl, daß die Zahl der Fälle, die zur Verfügung standen, eine recht kleine genannt werden muß. Doch lassen sich meiner Ansicht nach unter Berücksichtigung der bereits von anderer Seite erhobenen Befunde und im Hinblick auf die Besonderheit der einzelnen Krankheitsfälle recht bemerkenswerte und interessante Beobachtungen auch an diesem kleinen Material machen. Bei 4 von den 13 Paralysen war bei Verwendung der Serummenge von 0,5 kein Komplement in den Versuchen nachzuweisen. Diese Beobachtung wäre weniger erstaunlich, wenn es sich hierbei um lauter Fälle gehandelt hätte, die im Stadium äußerster Entkräftung und Kachexie der Untersuchung unterworfen worden wären. So lagen die Verhältnisse nur bei einem der Fälle: es handelte sich hierbei um eine Frau, bei der ungefähr 14. Tage nach der Blutentnahme rasch sich vergrößernde zahlreiche Dekubitalgeschwüre auftraten, die jeglicher Behandlung unzugänglich waren. Die Kranke starb ca. 4 Wochen später an völliger Entkräftung. Im zweiten Fall handelt es sich um eine erst seit kurzem hier befindliche Paralyse mit langsam zunehmenden tabischen Beschwerden, die sich jedoch in einem körperlich recht guten Kräftezustand befindet. Der dritte Fall ist ein stark dementer Paralytiker, dessen Krankheit während eines ca. einjährigen Anstaltsaufenthalts fast völlig stationär geblieben ist und der einen recht guten Kräftezustand aufweist. Im vierten Fall endlich handelt es sich um eine zeitweise etwas agitierte Paralyse bei einem Kranken von robustem Körperbau, der ganz im Besitz seiner körperlichen Kräfte ist und täglich in der Anstaltsgärtnerei beschäftigt werden kann. Gerade der Komplementmangel in einem Organismus, der, abgesehen von der Erkrankung des Nervensystems, körperlich so un- 
geschwächt erscheint, schien mir bedeutungsvoll zu sein. Im Gegensatz hierzu sah ich bei völlig entkräfteten männlichen und weiblichen Paralytikern noch bei der Serummenge von 0,05 und sogar bei 0,025 noch völlige Hämolyse eintreten. Es scheint dies darauf hinzuweisen, daß nicht nur die allgemeine Entkräftung des Körpers die Ursache der Analexie sein wird, sondern daß es sich um ganz besondere pathologische Vorgänge im Stoffwechsel des Körpers handeln wird. Darauf wird später zurückzukommen sein. Zunächst seien hier diejenigen Fälle besprochen, die - ohne zur Krankheitsgruppe der Paralyse zu gehören - bei 0,5 Hemmung zeigten. Es sind in der Dementia praecox-Gruppe 6, 3 Männer und 3 Frauen. Zwei von den Männern bieten körperlich nichts Besonderes, der dritte ist ein total verblödeter, syphilitisch infizierter Landstreicher, der in der Haft vor Jahren erkrankt ist. Es fand sich bei ihm positiver Wassermann in mäßiger Stärke im Serum, nicht im Liquor, und reichlicher Gehalt an Normalamboceptoren im Blute.

Die erste der drei Frauen ist eine körperlich sehr kräftige ca. 40 jährige Magd, bei der der ganze knorplige Teil der Nase durch einen alten, jetzt fast vernarbten Lupus zerstört ist. Die zweite Kranke ist eine blasse schwächliche Person, bei der - ohne daß Anhaltspunkte für Tuberkulose vorhanden wären - fast täglich auftretende enorme Schweißausbrüche auf tiefergehende Stoffwechselstörungen schließen lassen. Die dritte Kranke bietet körperlich nichts Besonderes.

Unter den epileptischen Kranken findet sich nur ein junges Mädchen, bei dem das Serum Analexie zeigt. Das Blut wurde bei der Kranken in einer Zeit entnommen, in der bei der Kranken fast täglich zahlreiche Anfälle aufgetreten waren. Die übliche Medikation war vor der Blutentnahme ausgesetzt worden.

Bei der Idiotie sind zwei Fälle zu besprechen: einmal ein beinahe über eine ganze Gesichtshälfte ausgedehnter, jeglicher Behandlung trotzender Lupus bei einem 20 jährigen Mädchen, und zweitens handelt es sich um einen Kranken mit ausgesprochener Neigung zu Furunkulose, der jedoch sonst nichts Besonderes bietet.

Bei den Senilen zeigt nur ein Apoplektiker bei 0,5 ccm keine Hämolyse, außerdem noch eine körperlich recht geschwächte, sonst nichts Besonders bietende Greisin.

Bezüglich der zwei Lupusfälle möchte ich erwähnen, daß in einem dritten Fall, bei dem es sich um einen sehr schweren, teils narbigen, teils ulcerösen Lupus handelt; der Komplementgehalt als ein reichlicher gefunden wurde. Nebenbei sei hier noch ein Fall von Pellagra erwähnt, der mehrfache Attacken von nervösen Störungen Durchfällen und Hauterscheinungen durchgemacht hatte und bei dem schon bei 0,3 Serum die Hemmung auftrat. Es bestand also hier starke Alexopenie.

Wir sehen also, daß außer bei Paralytikern noch bei anderen Kran- 
ken Analexie zur Beobachtung kommt, doch sind dies bis auf einige wenige, lauter solche, die in irgendeiner Hinsicht bemerkenswert sind. Es dürfte sich lohnen, in dieser Richtung weitere Versuche anzustellen. Für mich war zunächst die Paralyse, bei der die Analexie so außerordentlich häufig nachzuweisen war, von besonderem Interesse. Man ist geneigt anzunehmen, daß das eigentliche Wesen des paralytischen Krankheitsprozesses in irgendwelchem Zusammenhang mit der Erscheinung des Komplementmangels stehen muß. Besonders weist auf derartige Beziehungen der eine Fall hin, in dem bei einem körperlich kaum geschädigten Paralytiker das Komplement fehlte. Die Erkennung der zwischen dem Komplementmangel und dem paralytischen Kranheitsprozesse bestehenden Zusammenhänge dürfte freilich nicht ganz einfach sein. Sehen wir doch schon dadurch diese Frage erheblich kompliziert, daß eben nur in einem Teil der Paralysen das Komplement fehlt, während es in einem anderen Teil sogar in reichlicher Menge vorhanden sein kann. Es ergeben sich aus dieser Erkenntnis wieder neue Fragen; es könnte ja der Komplementmangel erst in einem gewissen Stadium des Krankheitsprozesses auftreten oder es könnten rein individuelle Besonderheiten die Entstehung desselben erst ermöglichen.

$\mathrm{Zu}$ einem weiteren Vorgehen in dieser Frage schien mir der Vorschlag Kafkas sehr bemerkenswert, nämlich zu versuchen, durch die Spaltung des Komplements in seine einzelnen Komponenten, Besonderheiten im Verhalten des Serums bei den Paralytikern aufzudecken. Da wir heute noch nicht mit Sicherheit wissen, ob das Komplement als komplexes Gebilde im Blutserum kreist, oder ob Mittelstück und Endstück getrennt nebeneinander bestehen, so wäre es sehr wohl denkbar, daß z. B. nur ein Teil des Komplements fehlt oder vermindert ist, während der andere in reichlicher Menge vorhanden ist.

Ich bediente mich zur Komplementspaltung der von Sachs und Altmann angegebenen Methode, die mir meist gute Resultate lieferte ich mischte 0,5 ccm Serum mit $4,1 \mathrm{ccm} 1 / 250$ Normalsalzsäurelösung, ließ das Gemisch eine Stunde bei Zimmertemperatur stehen und zentrifugierte ab. Das Sediment wurde in einem beliebigen Volumen destillierten Wassers aufgeschwemmt. Ich wählte die Aufschwemmung so, daß ein Kubikzentimeter derselben mit der entsprechenden Menge des fertigen Abgusses einer bestimmten vorher auch im Hauptversuch verwandten Serummenge entsprach. Der Abguß aus dem Zentrifugenglas wird filtriert, es werden hierauf $0,4 \mathrm{ccm} 10$ prozentige Kochsalzlösung hinzugefügt und mit $1 / 25$ Normalnatronlauge neutralisiert. Die Sedimentaufschwemmung enthält das Mittelstück, der Abguß das Endstück des Komplements.

In einem Fall, für den ich keine Erklärung finde, versagte das Verfahren. Ich hatte eine Probe mit 0,5 ccm Meerschweinchenserum an- 
gesetzt und beim Zusetzen der Normallsalzsäure die übliche Trübung bekommen. Sofort hinterher setzte ich eine neue Probe in denselben Mengen an mit demselben Serum, jetzt zeigte sich keine Spur von Trübung und selbst bei langem Zentrifugieren war keine Spur Sediment zu erhalten. Eine dritte auf dieselbe Weise angesetzte Probe verhielt sich ebenso. Ich kann für dieses verschiedene Verhalten bei ein und demselben Serum keine Erklärung finden.

Ich ging nun in der Weise vor, daß ich Mittelstück und Endstück für sich in der Menge von $1 \mathrm{ccm}$ ansetzte, in einem dritten Glas wurde 1 ccm Mittelstück mit demselben Volumen Endstück vereinigt. Die Blutkörperchen waren mit Amboceptor in genau derselben Dosis wie im Hauptversuch sensibilisiert. In denjenigen Fällen, in denen die Vereinigung von Mittelstück und Endstück das Hammelblut unbeeinflußt ließ, wurde dann jede dieser einzelnen Komponenten mit dem entsprechenden wirksamen Gegenstück aus Meerschweinchenserum zusammen angesetzt. Es konnten auf diese Weise bisher nur eine kleine Anzahl Seren untersucht werden, weswegen ich den Resultaten keine allzu große Bedeutung zusprechen möchte. Es zeigt sich, daß zunächst in allen denjenigen Fällen, bei denen im Hauptversuch wirksames Komplement nachzuweisen war, auch die einzelnen Komponenten in der entsprechenden Menge vereint wirkten. Häufig sah ich das Mittelstück. allein ohne Endstück deutliche Spuren von Hämolyse hervorrufen, das umgekehrte konnte ich nie beobachten.

In denjenigen Fällen, in denen im Hauptversuch kein Komplement nachzuweisen war, waren meist die einzelnen Komponenten, einzeln und zusammen auch unwirksam. Doch sah ich bei einem paralytischen Serum ohne Komplement vom Mittelstück eine Spur Hämolyse, das Endstück allein war ganz unwirksam. Mittelstück und Endstück zusammen gaben deutliche Lyse, ungefähr dieselbe Wirkung erhielt ich bei Vereinigung desselben Mittelstücks mit Meerschweinchenendstück. Im Gegensatz hierzu war Meerschweinchenmittelstück mit dem Endstück des Paralytikerserums gänzlich unwirksam.

Es wäre hieraus der Schluß zu ziehen, daß in dem Serum eines an progressiver Paralyse leidenden Kranken, bei dem anscheinend Komplementmangel besteht, sich die einzelnen Komponenten des Komplements nach der Spaltung nachweisen lassen. Es führt diese Erscheinung wieder auf das noch ungelöste Problem einer tieferen Kenntnis der komplexen Konstitution des Komplements bzw. seiner einzelnen Komponenten. Sie weist ja auf die Möglichkeit hin, daß ein totaler Mangel des Alexins gar nicht vorhanden ist, sondern daß nur ganz besondere eigenartige Bindungsverhältnisse, vielleicht reversibler Natur, vorliegen könnten, die den Nachweis des Komplements, vielleicht auch seine normalen Funktionen unmöglich machen. Weitere Untersuchungen über diese 
komplizierten Verhältnisse dürften vielleicht im Stande sein, einen Weg zu bahnen, der geeignet wäre, uns dem eigentlichen Wesen des paraIytischen Krankheitsprozesses, das wir noch so wenig kennen, näher zu führen, als es die bisher verwandten Untersuchungsmethoden vermocht haben. Es wäre ja denkbar, daß bei einer Krankheit, bei der eine so ausgiebige Zerstörung von nervösem Gewebe vor sich geht, die lipoidhaltigen Abbauprodukte einen direkten Einfluß auf die Entstehung oder den Verbrauch der Komplemente ausüben. Es ist bekannt, daß die Lipoide antikomplementär bzw. komplementbindend wirken und daß das Lecithin eine antikomplementäre Wirkung ausübt. Ob derartige Störungen der biologischen Prozesse an der Unheilbarkeit der progressiven Paralyse eine wesentliche Schuld tragen, darüber ist heute noch gar kein sicheres Urteil möglich.

Erwähnt sei hier noch, daß bei einer Anzahl der Paralysen die Normalamboceptoren im Blute fast völlig fehlten. Besonders war dies bei den Seren mit Analexie der Fall. Ich befinde mich mit dieser Angabe im Gegensatz zu Eliasberg, der bei Paralytikern reichlich Normalamboceptoren im Blute fand.

Wenn ich dazu übergehe, einige praktische Schlußfolgerungen in therapeutischer Hinsicht aus dem Vorstehenden zu ziehen, so darf ich wohl sagen, daß der Versuch, den Komplementgehalt bei denjenigen Paralysen, bei denen das Komplement im Blute fehlt, zu beeinflussen, sich lohnen wird bei einer Krankheit, die bisher einer therapeutischen Beeinflussung so wenig zugänglich sich erwiesen hat. Eine ganze Reihe von Substanzen sind bekannt dureh deren Einspritzungen eine günstige Beeinflussung des Komplementgehalts herbeigeführt wurde. So wurde nach Phloridzin, nach Pilokarpininjektionen, ferner nach Einspritzungen von physiologischer Kochsalzlösung, von Bouillon, Pepton, Hefe, Nuklein und Blutplasma eine Steigerung des Komplementgehalts gesehen. Doch gelang es mit allen diesen Substanzen, nur eine flüchtige Einwirkung zu erzielen. Eine günstige Beeinflussung einer Paralyse wäre indessen nur denkbar, wenn es gelänge, fortdauernd eine Vermehrung der Komplemente zu erzielen. Da uns noch kein sicher gangbarer Weg bekannt ist, den Körper in dieser Weise zu beeinflussen, so könnten wir vielleicht mit einem Verfahren eine möglichst weitgehende Einwirkung erzielen, das in der Dermatologie bisher recht brauchbare Resultate geliefert hat. Ich denke an die von Linser und Maier in Tübingen vor wenigen Jahren angegebenen Injektionen von größeren Mengen normalen frischen menschlichen Blutserums, die bei Schwangerschaftsdermatosen und Urticaria bisher so günstig wirkten. Es dürften allerdings nur von recht großen Serummengen und häufig wiederholten Injektionen größere Erfolge zu erwarten sein. Herr Professor Linser 
hatte die Freundlichkeit, mir mitzuteilen, daß er bis zu $100 \mathrm{ccm}$ subcutan bzw. intravenös injiziert habe, ohne irgend welche schädlichen Nebenwirkungen zu sehen.

Ich komme zum Schluß, indem ich das Resultat meiner Ausführungen kurz zusammenfasse:

Bei Erkrankungen aus der Gruppe der Dementia praecox, bei Epilepsie und teilweise auch bei Erkrankungen des Rückbildungsalters ist der Komplementgehalt des Blutserums ein verhältnismäßig hoher. Die Werte bei der Idiotie bleiben um ein beträchtliches hinter denjenigen der erstgenannten Krankheitsgruppen zurück.

Bei Epileptikern war nach den Anfällen keine wesentliche Differenz im Komplementgehalt nachzuweisen.

Bemerkenswerte Unterschiede zwischen Männern und Frauen traten nicht zutage.

Bei 2 Fällen von schwerem Lupus wurde Analexie gefunden, in einem 3. Falle von sehr schwerem Lupus war der Komplementgehalt reichlich.

Bei einer Kranken, die mehrere Attaken von Pellagra mit nervösen Störungen, Durchfällen und Hauterscheinungen durchgemacht hatte, war starke Alexopenie vorhanden.

Bei einem schwächlichen Kranken, der an multipler Sklerose litt, war der Komplementgehalt sehr gering.

Eine nicht tuberkulöse schwächliche Kranke, die seit 5 Jahren an häufig auftretenden enormen Schweißausbrüchen leidet, zeigte völligen Komplementmangel.

Bei 4 von 13 Paralysen fand sich kein Komplement im Blutserum, darunter bei einem körperlich sehr kräftigen widerstandsfähigen $\mathrm{Pa}$ tienten.

Die Spaltung des Komplements in Mittelstück und Endstück hat bisher zu keinem auffälligen Ergebnis geführt. Doch war bei einem Serum durch die Spaltung Hämolyse zu erzielen, nachdem der Versuch mit dem ungespaltenen Serum völlige Hemmung ergeben hatte. Es läßt dies darauf schließen, daß vielleicht in gewissen Fällen besondere Bindungsverhältnisse der einzelnen Komponenten des Komplements vorliegen, die bisher unbekannt sind. Die Versuche in dieser Richtung sind jedoch noch nicht abgeschlossen.

Der Gehalt des Paralytikerserums an Normalamboceptoren war in denjenigen Fällen, die kein Komplement zeigten, fast völlig aufgehoben, auch in einigen anderen Fällen war er sehr gering. Vielleicht hängt der Komplementmangel bei Paralyse mit dem ausgedehnten Zerfall von nervösem Gewebe bei dieser Krankheit zusammen, da bekannt ist, daß Lipoide wie Lecithin komplementbildend bzw. antikomplementär wirken. 
Um den Komplementgehalt des Blutes zu erhöhen und dadurch eine günstige Beeinflussung zu erzielen, läßt sich vielleicht das Verfahren von Linser und Maier verwenden, indem den Kranken häufige Einspritzungen größerer Mengen des Serums eines gesunden Menschen gemacht werden. Diese Einspritzungen müssen mindestens im Volumen von $100 \mathrm{ccm}$ gemacht werden, nachteilige Wirkungen hiervon sind bisher nie gesehen worden.

Es scheint mir, daß die neuerdings bei Paralyse wieder zur Anwendung gekommene Fiebertherapie sowie die Injektionen von Nuklein, die beide günstige Resultate geliefert haben sollen, auf dem Wege der Komplementerhöhung ihre günstige Beeinflussung ausüben, da experimentell erwiesen ist, daß sowohl durch Injektion von Tuberkulin wie durch Nuklein der Komplementgehalt des Blutes günstig beeinflußt werden kann.

Meinem verehrten Chef, Herrn Direktor Dabelstein, sei auch an dieser Stelle für das freundliche Entgegenkommen, durch das mir die Ausführung dieser Arbeit ermöglicht wurde, verbindlichst gedankt.

\section{Literaturverzeichnis.}

1. Sachs, Hämolysine und Cytotoxine des Blutserums, im Handbuch von $\mathrm{Kra}$ uss Levaditi: Technik und Methodik der Immunitätsforschung.

2. Gay, F. P. u. J. B. A yer, The demonstration of the alex ic activity of human blood. The journal of medical research 1907.

3. Eliasberg, Über das Fehlen des Komplements im Blute Lepröser. Dtsch. med. Wochenschr. 3\%. 1911.

4. Kentzler, Der Komplementgehalt des Blutes bei verschiedenen Formen der Lungentuberkulose. Berl. klin. Wochenschr. 11. 1905.

5. Moro, Die klinische Alexinprobe. Münch. med. Wochenschr. 21. 1907.

6. - ebenda 31.

7. - Ùber das Verhalten hämolytischer Serumstoffe beim gesunden und kranken Kind. J. F. Berg mann, Wiesbaden.

8. Kafka, Zeitschr. f. d. ges. Neurol. u. Psychiatrie Orig. 1, Heft 5. 1910.

9. - ebenda, Orig. 9, 2. Heft. 1912.

10. Weil u. Kafka, Wien. klin. Wochenschr. 24, 1911.

I1. - - Med. Klinik 34. 1911.

12. A. Mayer, u. Linser, Ein Versuch Sehwangerschaftsdermatosen durch Einspritzung von Schwangerschaftsserum zu heilen. Münch. med. Wochenschr. 52, 1910.

13. Linser, Über einige mit Serum geheilte Fälle von Urticaria. Med. Klinik 4. 1911.

14. - U̇ber Hauterkrankungen bei Schwangerschaft und deren Heilung. Dermatol. Zeitschr. 1911. 